\title{
Reflexões sobre o magnetismo animal: contribuições para revisão da história da psicologia
}

\author{
Reflections on animal magnetism: contributions \\ to a review of the history of psychology
}

Maurício da Silva NEUBERN ${ }^{1,2}$

\begin{abstract}
Resumo
Este artigo procura fornecer subsídios para uma alternativa de compreensão histórica sobre o magnetismo animal, de modo a realçar sua importância na construção da psicologia. Nesse sentido, busca-se enfatizar o papel das instituições e práticas sociais que influenciaram de forma decisiva a condenação desta proposta. Na mesma linha de reflexão, visa-se também destacar algumas das incompatibilidades epistemológicas com o projeto moderno de ciência, que também contribuíram significativamente para a rejeição do magnetismo animal. Por fim, o artigo é concluído com uma reflexão sobre a necessidade de revisão da noção de ciência presente nas referências dominantes da história da psicologia, que, geralmente, restringem-se a questões lineares e metodológicas e desprezam os processos intersubjetivos e sociais que atuam na construção desta área de conhecimento.
\end{abstract}

Unitermos: Epistemologia. História da psicologia. Subjetividade. Magnetismo animal.

\begin{abstract}
The present article intends to provide support for an alternative to a historical understanding of animal magnetism, highlighting its importance in the construction of psychology. Accordingly, the article attempts to emphasize the role of social institutions and practices which have had a decisive influence on the denunciation of such proposals. Along the sameline of thinking, it also aims to highlight some of theepistemiological incompatibilities that lie in the modern science project, which have also contributed significantly to the rejection of animal magnetism. Finally, the article ends by reconsidering the need for a review on the very notion of science existing in the main reference works on the history of psychology, which are generally limited to methodological and linear issues and therefore disregard the inter-subjective and social processes at work in the construction of psychology as a science.
\end{abstract}

Uniterms: Epistemology. History of psychology. Animal magnetism. Subjectivity.

É muito comum que as versões dominantes da história da psicologia, inspiradas pelo projeto moderno de ciência ${ }^{3}$, possuam um caráter linear e progressivo, em que o passado de erros e mitos pré-científicos seja substituído por sistemas científicos e triunfantes (Benjafield, 1996; Morel, Bourgeron \& Roudinesco, 2000; Viney \& King, 1998). Seguindo-se o ímpeto moderno de desvendar o mundo sem refletir a si mesmo, isto é, suas

\section{VQV}

1 Instituto Milton H. Erickson de Brasília. SEPS 707/907, Ed. San Marino, Sala 227/228, 70330-700, Brasília, DF, Brasil. E-mail: <mneubern@hotmail.com>.

2 Pontífícia Universidade Católica de Campinas, Centro de Ciências da Vida, Programa de Pós-Graduação em Psicologia. Campinas, SP, Brasil.

3 A idéia de projeto moderno de ciência é explorada por Santos (1987; 2000) e se refere a um projeto inspirado no paradigma dominante da ciência. Tal paradigma baseia-se em princípios isomórficos (isto é, de revelação linear da realidade), com noções como explicação, predição e controle, e se coloca como um conhecimento superior aos outros por possuir um acesso privilegiado à realidade. 
condições institucionais e práticas sociais (Demo, 1998; Fourez, 1995; Morin, 1991; Neubern, 2003; Stengers, 1995), tais referências históricas conferem ênfase a um pretenso progresso teórico e metodológico, sem praticamente discutir e problematizar os processos institucionais, os jogos de força entre pessoas e grupos e o cenário social em que a dita evolução teria ocorrido. Em nome da razão, o foco se restringe às relações lineares entre o sujeito e seus objetos, como se a ciência consistisse apenas em um problema de métodos e teorias que revelassem a realidade. Parecem conferir um teor pacífico e previsível, como se os protagonistas implicados se conformassem com as luzes da razão, como se não houvesse mais disputas entre os diferentes sistemas envolvidos e a eliminação dos sistemas rivais fosse simples conseqüência de superioridade metodológica dos vencedores (Marx \& Hillix, 1978; Roudinesco, 1986; Viney \& King, 1998).

Nesse sentido, o período histórico que envolve o magnetismo animal, que abrange o final do século XVIII e boa parte do XIX, na França, é geralmente alvo de omissões e distorções que denunciam uma tentativa de evitar, por parte das versões históricas dominantes, qualquer parentesco entre este movimento e a psicologia moderna (Méheust, 1999). Quando não se encontra completamente excluído (Marx \& Hillix, 1978), ele é freqüentemente visto como um movimento ligado ao charlatanismo denunciado pelas instituições científicas (Gay, 2002; D. Schultz \& P. Schultz, 1981), ou como um sistema teórico e terapêutico inconsistente que não resistiu às exigências metodológicas do projeto moderno de ciência (Figueiredo, 1992; Roudinesco 1986). Partindo de um pressuposto isomórfico de ciência (Gergen, 1996; Gonzalez Rey, 1997), tais perspectivas restringem a rejeição da legitimação do mesmerismo ao contexto experimental, como se o reconhecimento científico consistisse exclusivamente em procedimentos metodológicos restritos à relação sujeito-objeto e alheios ao cenário social e às tramas intersubjetivas. Entretanto, tais referências pouco mencionam acontecimentos e processos que poderiam contradizer suas prerrogativas, tais como os detalhes e fragilidades das experimentações designadas para avaliar o magnetismo animal, os mecanismos utilizados para impor silêncio aos dissidentes, as tramas e oposições institucionais aí presentes e suas relações com o contexto social na França da época (Carroy, 1991; Crabtree, 1993; Darntorn, 1968; Ellenberger, 1970; Laurence \& Perry, 1988; Méheust, 1999). Menos ainda consideram que tais dimensões tenham possuído um papel relevante na construção da marginalidade que se impôs historicamente ao magnetismo animal.

Sendo assim, o objetivo deste artigo é fornecer subsídios para uma alternativa de compreensão histórica do magnetismo animal que realce sua importância na construção da psicologia moderna, inspirada pelo projeto moderno de ciência. Nesse sentido, são enfocados dois pontos específicos. Primeiramente, o que destaca o papel decisivo da dimensão institucional e das práticas sociais que acabaram condenando o magnetismo animal à marginalização; tal ponto consiste em criticar a restrição metodológica e teórica que as versões dominantes conferem ao mesmerismo, destacando um cenário social pouco favorável à sua aceitação como tema de interesse científico. Em segundo lugar, será atribuído destaque às oposições epistemológicas que garantiram uma condição ora de exclusão, ora de distorção do magnetismo animal, nas referências históricas da psicologia. Parte-se aqui da idéia de que a rejeição ao magnetismo animal não consiste necessariamente em um problema metodológico, mas em uma incompatibilidade epistemológica com o projeto moderno de ciência (Chertok \& Stengers, 1989). Enquanto o projeto moderno de ciência se fundava em noções como a explicação, predição, controle e isomorfismo, o mesmerismo se baseava em noções como a influência e a subjetividade, vindas em boa parte da Renascença (Koyré, 1971). Assim, o artigo destaca algumas dessas noções e o modo como sua presença nas concepções do magnetismo animal contribuíram para a condenação das comissões e da história da psicologia (Méheust, 1999).

\section{As práticas sociais da condenação}

Em 1784, o rei da França Louis XVI determinou duas comissões ${ }^{4}$ de renomados cientistas para avaliar a pertinência científica da proposta terapêutica do

\section{$\boldsymbol{\nabla} \boldsymbol{\nabla} \boldsymbol{\nabla}$}

4 A primeira comissão, de 12 de março, era composta por Borie, Sallin, d'Arcet e Guillotin (da Faculté de Médecine) e por Bailly, Lavoisier, LeRoy, Bory e o então embaixador americano, Benjamin Franklin (da Académie des Sciences). A segunda comissão, de 5 de abril, era composta por membros da Societé Royale de Médecine, como Poissonnier, Caille, Mauduyt, Andry e o naturalista Laurent de Jussieu (Laurence \& Perry, 1988). 
magnetismo animal, dada a enxurrada de polêmicas que se arrastavam sobre o tema (Bertrand, 1826/2004; Crabtree, 1993; Ellenberger, 1970; Laurence \& Perry, 1988). Procedendo a um conjunto de experimentos de cegos e duplos-cegos, os cientistas decidiram pela inexistência do dito agente estranho - o fluido magnético - apontado por Mesmer como responsável pelas curas, e concluíram que estas ocorreriam devido à imaginação (Bailly, 1826/ 2004a; Bersot, 1853/2005). As conseqüências que daí surgiram foram marcantes, posto que muitos professores foram ameaçados e até excluídos dos quadros das sociedades de ciência, e quem quer que associasse seu nome a tal prática poderia sofrer sérias retaliações no meio social. Além de ser concebido como uma quimera, o magnetismo animal foi considerado uma prática perigosa, na qual um médico inescrupuloso poderia facilmente se aproveitar da fragilidade das pacientes e pervertê-las sexualmente (Bailly, 1826/2004b; Bersot, 1853/2005). Mas é importante destacar nesta breve passagem que, nesse momento, inaugurou-se uma linha de oposição sistemática inspirada nos ideais científicos da época, em que era necessário rejeitar e excluir qualquer doutrina ou prática que ameaçasse o projeto moderno de ciência.

Desse modo, verifica-se que, ao longo das querelas em torno do magnetismo animal, os discursos produzidos contra ele veicularam a idéia de uma doutrina irracional e não científica; em tais discursos as instituições dominantes mantiveram seu ideal de regulação social ativo (Santos, 2000), impedindo ameaças de transformação não só do conhecimento, mas da própria sociedade moderna. Isto porque a doutrina de Mesmer (1779/2005) e seus seguidores apresentava não apenas uma proposta terapêutica, mas um ambicioso projeto de sociedade. Além das relações estreitas com a maçonaria, muitos de seus adeptos eram críticos mordazes do colonialismo europeu, principalmente das políticas escravocratas, e da acentuada hierarquia social francesa (Darntorn, 1968; Laurence \& Perry, 1988). O parentesco com sistemas renascentistas (Ellenberger, 1970; Koyré, 1971; Méheust, 1999), a crítica ao autoritarismo médico e a associação com doutrinas espiritualistas (Bergé, 1995) fazia dos magnetizadores o alvo preferido das instituições médicas e da Igreja Católica, bastante incomodada com suas propostas subversivas. Até mesmo as noções de família viam-se questionadas, uma vez que as mulheres, que desem- penhavam um papel fundamental na produção dos fenômenos, ganhavam certa notoriedade pública, em uma época em que seus papéis deveriam ser restritos ao espaço privado e doméstico do lar burguês (Edelman, 1995).

Do ponto de vista das práticas sociais, chama a atenção no processo de avaliação do magnetismo animal o elevado número de contradições, algumas delas grotescas, produzidas pelos cientistas das comissões e as instituições às quais pertenciam. Foram realizadas dezessete experiências, obedecendo a um mesmo princípio: o sujeito da experiência deveria estar cego quanto à manipulação de variáveis do processo (Bertrand, 1826/2004). De início, solicitou-se a algumas pessoas que descrevessem a influência do dito fluido durante um processo de magnetização, ao qual alguns membros da própria comissão se submeteram. Como os relatos não coincidiam, indo de formigamentos e calores a nenhuma sensação, a comissão apelou para o uso de sujeitos "cegos". Assim, foi dito a uma jovem com olhos vendados, habituada ao magnetismo, que logo ela seria magnetizada por um expert no assunto o que, de fato, não ocorreu. Mesmo assim, ao termo de alguns minutos, a jovem relatou sentir as sensações típicas da influência do fluido e entrou em crise magnética. Em outra ocasião, pediu-se ao magnetizador que magnetizasse uma árvore em um pomar e, a um jovem sensível à percepção do fluido, que descobrisse qual delas havia recebido tal influência. Ele se dirigiu a outra árvore e, ao tocá-la, desenvolveu a crise.

Um primeiro aspecto importante foi a própria insistência em torno da metodologia, cujo caráter experimental de controlar variáveis poderia ser questionado, diante de um conjunto de fenômenos ainda pouco explorado. A metodologia de cegos e duplos-cegos baseava-se na idéia de que a existência do fluido estaria condicionada à sua percepção física pelos pacientes, o que era contestado pelos magnetizadores, para quem o fluido seria perceptível por seus efeitos enquanto veículo de cura ao longo de um processo de alguns meses (Deleuze, 1813/2004). Foi por isso que Jussieu (1826/2004), empregando uma metodologia naturalista, com observações de campo freqüentes, chegou a um resultado bastante distinto das comissões: embora reconhecesse que havia, como possíveis causas dos efeitos magnéticos, o toque, a imitação e a imaginação, 
ele também reconheceu a existência de um agente, que designou calor animal. Apenas essa divergência entre um dissidente e as comissões já propiciava ensejo para que a discussão continuasse, uma vez que, pensando-se em termos de Popper (1973), por exemplo, a idéia de um agente estranho não teria sido inteiramente falseada e, em conseqüência, a discussão deveria ser mantida em aberto, tal como ocorre na atualidade (Stengers, 1995). Entretanto, as conclusões de Jussieu foram alvo de uma rejeição sistemática; não passaram por qualquer discussão entre os membros das instituições envolvidas, que se limitaram a repetir, sem abrir espaço para discussão, a conclusão das comissões: a de que a imaginação era responsável pelos fenômenos antes atribuídos ao magnetismo animal (Bertrand, 1826/2004; Deleuze, 1813/2004). A insistência metodológica foi acompanhada de uma rejeição sistemática a qualquer alternativa de pesquisa, o que trouxe como conseqüência a impossibilidade do debate e da discussão.

Ante um contexto desfavorável, a escolha metodológica também sofreu profunda influência dos mecanismos de regulação. Isto porque o método foi alçado a uma condição absoluta sem qualquer questionamento sobre sua legitimidade diante de um novo campo de pesquisa, como se o que não respondesse às exigências metodológicas propostas tivesse sua realidade negada, mesmo que os acontecimentos indicassem o contrário. Desprezando o sistema de crenças dos magnetizadores, as comissões procederam a uma série de mutilações do campo de pesquisa, impondo seus procedimentos da forma como achavam que deveriam ser aplicados, independentemente das possíveis necessidades da realidade estudada. Não importava que esses novos terapeutas asseverassem que o fluido era imperceptível na maioria das vezes aos sentidos físicos, e que seu efeito só poderia ser observado indiretamente pelas curas: o importante era que os procedimentos criavam um contexto de confiabilidade, e qualquer fenômeno real deveria ser submetido às exigências. Assim, sem um estudo prévio do novo campo, como buscou realizar Jussieu (1826/2004), e com inúmeras crenças prévias sobre a pesquisa, as comissões fabricaram um contexto destinado ao fracasso do magnetismo animal, por meio de uma metodologia que não poderia reconhecer e estabelecer um diálogo 442 aberto com tais fenômenos (Carroy, 1991; Chertok \&
Stengers, 1989). Vale lembrar que poucas noções hoje consagradas em psicologia, que possuem necessidades específicas de investigação (Demo, 2000; Gonzalez Rey, 2005), resistiriam a tais exigências metodológicas.

Porém, a contradição mais gritante foi referente à própria imaginação (Chertok \& Stengers, 1989). Isto porque, se a imaginação era concebida como causa de curas efetivas, era necessário que fosse isolada e submetida aos mesmos procedimentos metodológicos, o que não ocorreu. Além disso, era necessária uma definição sobre a imaginação, uma tentativa de explicação sobre a mesma e seus curiosos mecanismos de cura, o que também ficou sem respostas. Desse modo, ao invés de elucidar as causas de acontecimentos ainda tão desconhecidos, atribuídos a um fluido pouco explorado, as comissões apontaram uma nova causa tão obscura quanto o dito fluido, sem apresentar-Ihe maiores esclarecimentos. Entretanto, mesmo sob uma conclusão frágil e contraditória, as instituições envolvidas se autorizaram a condenar o magnetismo animal, a ridicularizar seus praticantes e ameaçá-los de desligamento caso insistissem em objetar e expor suas opiniões (Ellenberger, 1970; Laurence \& Perry, 1988). Segundo Bertrand (1826/2004), os integrantes da Faculté de Médecine foram obrigados, sob ameaça de exclusão, a assinar um termo no qual rejeitavam publicamente suas relações com o mesmerismo, o que resultou no afastamento de muitos membros.

Mas o que talvez tenha sido mais surpreendente em termos dessa influência regulatória foi o teor da resposta proferida pelas comissões. Era necessário que uma resposta fosse dada, que uma satisfação fosse prestada à sociedade, como também à própria realeza, que havia mostrado um interesse direto no assunto. Contudo, a resposta dada - a imaginação - não cumpriu com o propósito científico (Bachelard, 1938), segundo o qual a resposta implica em uma continuidade de perguntas e uma abertura à reflexão que envolve os cientistas interessados na mesma, aqueles cujas práticas se mobilizam em torno dessa resposta (Stengers, 1996). As conseqüências posteriores à conclusão das comissões em termos de práticas sociais no seio das instituições científicas foram, basicamente, de duas ordens. Por um lado, construiu-se a idéia de que a imaginação era um veredicto final sobre o qual não caberiam mais 
quaisquer pesquisas e quaisquer outras investigações, já que os segredos dos magnetizadores teriam sido desnudados de vez. Assim, a imaginação se tornou um campo ao mesmo tempo morto e proibido, um campo de inércia científica que não merecia maiores atenções dos pesquisadores sérios. O problema se dava pelo fato de que a imaginação encontrada pelos cientistas em nada diferia da imaginação de seu maior inimigo - o senso comum - uma vez que não havia sido submetida aos mesmos procedimentos, nem definida ou conceituada, nem mesmo explicada em seu modo de ação. Reinava o silêncio. Mesmo que várias curas efetivas continuassem a ocorrer por quase um século, indo de Puységur (1784/2001) a Esdaile (1846/1989), o terreno foi fechado e interditado a quem quer que desejasse manter sua reputação de cientista.

Por outro lado, vários mecanismos de coação foram ativados, e abrangeram desde a postura de retirada de espaço para discussão e pesquisa até punições mais severas, como as expulsões e ridicularizações públicas, movidas por panfletos, reportagens de jornal e cartas que atacavam diretamente os adeptos do magnetismo animal, sem contar que qualquer relação com tal movimento poderia ser facilmente associada à desagradável acusação de assédio sexual de mulheres (Deleuze, 1813/2004; Ellenberger, 1970; Laurence \& Perry, 1988). O contexto social se tornou tão arredio ao mesmerismo que, na segunda metade do século XIX, a própria máquina jurídica do Estado passou a ser utilizada para punir legalmente aqueles que se aventurassem a qualquer prática que dele se aproximasse (Edelman, 1995).

Nesse sentido, é possível perceber que certos momentos anteriores ao processo de avaliação já se configuravam desfavoráveis à proposta de Mesmer, a começar pela escolha dos próprios membros das academias, para quem os fenômenos jamais haviam sido alvo de alguma observação mais sistemática. Entre os membros das instituições não havia um sequer que demonstrasse interesse ou simpatia pelo tema, e sua condição social não parecia pesar a favor de uma postura de neutralidade (Laurence \& Perry, 1988). É importante destacar que o histórico das relações entre Mesmer e as instituições acadêmicas na França já se encontrava bastante desgastado, fosse pelos relatos pejorativos vindos ainda de Viena, onde Mesmer teve vários problemas com a comunidade científica, fosse pelos desagradáveis embates anteriores com as próprias instituições francesas, agora encarregadas de examinar seu trabalho. Em um desses episódios, um de seus discípulos mais ilustres, Charles d'Eslon, foi duramente criticado na Faculté de Médecine, suspenso por um ano e ameaçado de exclusão de seus quadros (Crabtree, 1993; Laurence \& Perry, 1988). Cabe ressaltar que os opositores de Mesmer eram pessoas com elevada condição social, que Ihes conferia destaque e uma série de privilégios junto a setores importantes da sociedade. Em sua maioria eram nobres e membros da alta burguesia, e transitavam em um tecido social que poderia Ihes propiciar reconhecimento e riquezas, permitindo-Ihes acesso a instituições e pessoas de considerável relevância para a sociedade francesa. Uma vez que a posição social de tais sujeitos era entrecortada por várias formas de discursos e trocas sociais que lhe garantiam considerável status quo, propiciando-lhes identidade e visibilidade social, torna-se compreensível que muitos deles pudessem não estar disponíveis para dialogar com uma proposta tão subversiva quanto a de Mesmer.

A dimensão institucional, portanto, desempenhou um papel decisivo na construção de uma psicologia a ser colonizada pelo projeto moderno de ciência. Mesmo sem muita visibilidade nas referências históricas, ela se constituiu como cenário de batalhas cruéis, a partir das quais se decidiu o que poderia ou não ser considerado de alçada científica. O mais curioso, porém, é que para atingir tal fim, ela se colocou na posição de poder contradizer os próprios princípios científicos, impondo o silêncio e estabelecendo retaliações para os sujeitos subversivos. Assim, de forma bastante ilustrativa, é possível considerar que o papel desempenhado pela dimensão institucional nessa história é fundamental para dar continuidade à reflexão na qual a ciência é um empreendimento humano sujeito a todas as vicissitudes desta condição. Isso não implica em afirmações simplistas, como as que sustentam que tudo é uma questão de construção social (Hacking, 1999; Latour, 1995; Stengers, 1995), mas apenas na importância de se considerar que a construção da ciência, principalmente da psicologia, não se restringe a uma questão ontológica completamente alheia às trocas humanas e suas vicissitudes institucionais. 


\section{O Esquecimento em nome da razão}

Semelhante oposição talvez encontre sentido sob uma análise do projeto moderno de ciência (Demo, 1998; Fourez, 1995; Santos, 1987; 2000; Stengers, 1995) no qual se inspiraram as ciências modernas, inclusive a psicologia. O projeto moderno de ciência propôs um saber capaz de ir além das ilusões aparentes do mundo para atingir as verdadeiras leis que regem a natureza, de maneira que, ao refleti-la como em um espelho (daí a noção de isomorfismo), fosse possível conceber um conhecimento legitimamente objetivo. A ciência se ergueu como um conhecimento superior aos outros, pois, tendo acesso às leis universais e invariáveis, seria capaz de prever e controlar a natureza, o que implicou uma verdadeira revolução nas sociedades ocidentais (Demo, 1998; Fourez, 1995; Morin, 1991; Santos, 2000; Stengers, 2000). A essa altura, é correto afirmar que as diferentes expressões da psicologia não se ajustaram completamente a tais pressupostos, principalmente devido a suas diferentes matrizes epistemológicas (Figueiredo, 1992, 1996). Entretanto, também é coerente conceber que, além da diversidade teórica e metodológica, as diversas escolas de psicologia, ou ao menos a maioria delas, tentaram a seu modo incorporar o projeto de ciência, principalmente no tocante ao princípio isomórfico, o que torna possível apontar muitas semeIhanças entre a psicanálise de Freud e a psicologia experimental behaviorista (Neubern, 2000, 2003; Stengers, 1996), que durante muito tempo rivalizaram mutuamente para buscar a hegemonia científica do campo psicológico.

Tal concepção permite interpretar que a adesão ao isomorfismo implicava também em uma tentativa de manter a legitimidade científica, por meio da incorporação de uma ou mais noções mestras, tais como a explicação, generalização, predição e controle, que poderiam adotar diferentes formatos dentro de cada psicologia específica. Porém, ela significava algo ainda mais importante: era uma questão de sobrevivência para qualquer sistema que ambicionasse ser reconhecido como científico (Demo, 2000; Stengers, 1995, 2000). As escolas de psicologia que trouxessem a herança de uma subjetividade renascentista (Figueiredo, 1992; Koyré, 1971; Méheust, 1999; Neubern, 2003), precursora do magnetismo, deveriam se adaptar rapidamente ao cenário moderno, propondo-se um exorcismo episte- mológico que eliminasse de vez noções como elfos, salamandras, integração com o mundo, inteligência (enquanto criação e autonomia), sujeito e vida. Quem quer que não impusesse a si mesmo semelhante mutilação estaria fadado a um exílio cruel e extremo, longe de qualquer perspectiva de cidadania junto às ciências modernas.

É justamente nesse ponto que se torna possível compreender algumas facetas referentes ao esquecimento histórico profundo que recaiu sobre o magnetismo animal, cujos pressupostos mais centrais entravam em choque com a racionalidade científica dominante (Méheust, 1999; Stengers, 2002). A princípio, muitos dos fenômenos produzidos nos settings do mesmerismo não poderiam ser replicados e controlados, pois sua ocorrência se dava à revelia do sujeito e do magnetizador. Além de ser nascido em um contexto clínico, o que já trazia implicações graves diante do projeto de ciência (Carroy, 1991), tal prática estava perpassada por noções marginais, como a idéia de uma natureza sábia e inteligente que não poderia ser controlada; a ruptura da separação sujeito-objeto, diante da qual a relação terapêutica era a de uma influência mútua e constante que rompia com a própria alteridade; e a quebra que freqüentemente ocorria em relação aos próprios limites da realidade conhecida. Mas o que parecia realmente trazer transtornos para os guardiões do projeto moderno de ciência era a ruptura com o próprio isomorfismo, posto que o paciente magnetizado dificilmente poderia oferecer dados confiáveis e depurados, pois não era possível saber até que ponto suas expressões se davam por um processo de revelação da realidade (portanto, isomórfico) ou se por uma complacência quanto a expectativas de seus magnetizadores (Chertok \& Stengers, 1989). Dito de outro modo, não seria possível distinguir se as expressões consistiam em fatos ou em artefatos construídos para atender às necessidades daqueles que se dispunham a curar seus males ou provar a existência do magnetismo animal.

Assim, devido ao envolvimento com princípios tão opostos ao projeto de ciência, o mesmerismo transformou-se em um campo maldito, que legou duas grandes conseqüências históricas. Em um primeiro plano, muitos de seus autores foram absorvidos pelo esquecimento sistemático, apesar de suas importantes contribuições para a construção da psicologia. Como 
já visto, é certo que as citações sobre Mesmer não são tão raras, mas mesmo assim são geralmente marcadas por uma série de deformações históricas que pouco permitem compreender sua proposta e os meandros do processo de condenação da mesma. O marquês de Puységur (1784/2001), quando não completamente esquecido, geralmente é retratado como um sujeito crédulo e ingênuo (Barrucand, 1987; Roudinesco, 1986), sem que se coloque para discussão as instituições que criou, os jornais que fundou e a importância de seu papel para a construção da psicoterapia moderna (Chertok \&Saussure, 1996; Méheust, 1999; Peter, 1999). Seguindo a mesma sina, o jovem médico Alexandre Bertrand, praticamente desconhecido dos psicólogos atuais, foi um dos primeiros a conceber um campo psicológico (Bertrand, 1826/2004), ao propor uma interface entre medicina e filosofia - a medicina da imaginação ou psicologia - que inspirou adeptos e contraditores famosos como Taine, Maine de Biran, Bergson e Janet, por quase oito décadas, na França do século XIX, envolvendo instituições, teses e pesquisas (Carroy, 1991, 1993). Assim, a construção das versões dominantes de história da psicologia ocorreu como se qualquer parentesco com este tema devesse ser categoricamente negado, sob a pena de ter sua legitimidade colocada sob suspeita (Chertok \& Stengers, 1989; Méheust, 1999). Talvez tenha sido mais prudente operar, em nome da razão, profundas mutilações na própria história, a fim de salvaguardar o tão comprometido reconhecimento conseguido em meio a duras e numerosas batalhas.

Entretanto, tal prevenção não se restringiu a nomes e obras, mas também a todo um campo de reflexão que passou a ser amaldiçoado diante da proposta científica, como se deu especificamente com a hipnose. Embora fosse herdeira histórica do mesmerismo, seus promotores buscaram concebê-la como um método legitimamente científico, desvencilhado de noções místicas, como fluidos e imaginação, para se fundamentar nas estruturas nervosas do cérebro (Carroy, 1991; Méheust, 1999). Foi-Ihe dada a missão de colonizar sob uma ótica, enfim, racional, o terreno inóspito dos processos psíquicos e subjetivos, antes visitado apenas por figuras suspeitas como magnetizadores, sonâmbulos e médiuns.

Foi assim que o jovem Freud (Chertok \& Stengers, 1989), atraído pelo carisma de Charcot, elegeu-a ini- cialmente como o método privilegiado de pesquisa e cura das neuroses. Entretanto, como os problemas epistemológicos já citados não se fizeram demorar, ele logo se viu emaranhado nas dúvidas para distinguir, no uso da hipnose, os dados confiáveis da realidade, dignos de uma pesquisa científica, dos possíveis artefatos produzidos pelos pacientes, ansiosos por agradar seus médicos, o que o levou a abandonar tal método, substituindo-o pela psicanálise (Chertok \& Stengers, 1989). A partir daí, a hipnose foi alçada a uma condição maldita, cultivada por décadas em inúmeros círculos profissionais e acadêmicos, para quem tal método, além da complacência, era ineficiente, não atingia as causas dos sintomas e poderia induzir os pacientes a uma série de perigos (Melchior, 1998; Neubern, 2004, 2006).

No entanto, o ponto que mais se destaca nesse processo é que os mesmos mecanismos que silenciaram os acontecimentos referentes ao magnetismo animal repetiram-se com a hipnose. Isto porque Freud (1937/1996a), ao final de sua vida, sustentou algumas posições que reviam consideravelmente suas opiniões quanto à hipnose. Para ele, ainda não havia sido encontrado substituto algum para a sugestão, de maneira que a psicanálise, apesar das contribuições, não se apresentava mais como o método por excelência capaz de fazer coincidir ciência e terapia. Porém, não só os psicanalistas, como ainda todos que se encontravam sob sua influên-cia, deixaram passar despercebidas colocações de profunda pertinência para a revisão e discussão sobre o tema (Chertok, 1989; Cherok \& Stengers, 1989). Era preferível que se mantivesse viva a vontade de ciência acesa pelo criador da psicanálise do que dar espaço para qualquer pensamento que pudesse contradizê-la, independente de sua pertinência.

\section{Considerações Finais}

Uma das conseqüências mais preponderantes dessa discussão refere-se às limitações da noção de ciência presente nas perspectivas dominantes da história da psicologia. Isto porque, mesmo que se faça um esforço em aceitar a perspectiva linear e progressiva aí reinante, na qual a ciência é definida exclusivamente por uma relação isomórfica, as contradições são numerosas e indiscutíveis. A série de equívocos que poderiam comprometer a legitimidade dos experimentos sobre 
o magnetismo animal, como os problemas de imaginação e método aqui levantados, não impediu que Mesmer fosse visto e retratado nas referências históricas como um charlatão ou visionário criador de um sistema incapaz de resistir às exigências do método científico. As várias mutilações envolvidas na concepção do método, o menosprezo conferido a métodos distintos, como o de Jussieu, e a desqualificação de um campo tão promissor de estudo, como a imaginação, que não foi explicada, conceituada ou estudada sistematicamente, não foram suficientes para levantar suspeitas sobre a condição de marginalidade à qual o magnetismo animal foi alçado nas versões dominantes da história da psicologia. Assim, uma das conclusões que se destacam nesse trabalho é a necessidade de uma crítica sobre a própria noção de ciência defendida nas versões dominantes da história da psicologia, o que pode ser discutido em dois sentidos intimamente integrados.

Primeiramente, trata-se de uma noção que mesmo hoje traz dificuldades consideráveis, uma vez que pressupõe uma série de exigências que nem sempre são atendidas pelas diversas escolas de psicologia diante de um terreno tão nebuloso e traiçoeiro como o da subjetividade. Perspectivas de controle e predição, de unidade científica em termos de teorias e métodos, de mensuração e da criação de um contexto realmente confiável que possa fazer calar as dúvidas e diferenças (Stengers, 1995) são razões para que os psicólogos se debatam em lutas ferozes, ou ingenuamente alimentem a idéia de que um dia a psicologia gozará de uma unidade legítima, como suas outras irmãs que encarnaram o projeto de ciência com mais sucesso, como a física (Figueiredo, 1996). Ora, defender essa perspectiva em termos históricos consiste em um ponto de vista bastante problemático e questionável, uma vez que não contempla a diversidade de perspectivas que se reúnem em torno do termo psicologia, nem mesmo problematiza os conflitos decorrentes da falta de unidade e de uma adesão incompleta a essa noção de ciência. As proibições que se exerceram em torno da imaginação talvez tenham sido um modo de tentar prevenir tais problemas, ainda insolúveis, que resultam da proposta de lançar o projeto moderno de ciência sobre o estudo da subjetividade. Em segundo lugar, a noção de ciência apresentada nas versões dominantes produz profundas mutilações sobre dimensões, processos, autores e 446 acontecimentos de grande pertinência na construção histórica da psicologia. Em nome de uma racionalidade confiável, percebe-se um conjunto de mecanismos de interdição que ocultaram as práticas sociais e trocas subjetivas que ocorreram no seio das instituições oficiais e que desempenharam um papel decisivo na condenação do magnetismo animal, na maldição lançada sobre a hipnose e na efetivação das linhas epistemológicas dominantes da psicologia.

Os acontecimentos brevemente descritos sobre a avaliação do mesmerismo permitem conceber que as contradições apresentadas nos procedimentos e decisões referentes à pesquisa desenvolvida possuíram uma estreita relação com outras dimensões de grande importância, raramente discutidas nas referências dominantes, que desempenharam um papel central na condenação dessa proposta terapêutica. Os conflitos entre Mesmer e as instituições oficiais, as indisposições criadas por instituições sociais, como a Igreja e o Estado, e as próprias dificuldades epistemológicas presentes, foram fundamentais para que o mesmerismo fosse excluído dos interesses científicos a ponto de se tornar, para muitos, um mero registro histórico. Foi assim que os acontecimentos passaram a possuir um caráter proibitivo, ao invés de constituírem possibilidades de investigação e construção de conhecimento. Enquanto a imaginação e suas curas deixaram de se tornar um campo de estudos promissor e fértil e se tornaram um assunto sem interesse para os homens de ciência, a dimensão erótica, ao invés de ser compreendida como um componente da relação terapêutica, como o fez Freud (1937/1996b), foi concebida como um perigo de perversão sexual que deveria justificar a proibição, pelo próprio Estado, da proposta de Mesmer.

Torna-se, portanto, necessário desenvolver um olhar que possa abrir um novo campo de reflexão, de maneira a recontar a história dessa ciência, não dentro do espectro estreito da relação isomórfica de um pesquisador em face de seus objetos de estudo, mas, sobretudo, como um processo complexo no qual seja possível conceber o cruzamento de registros institucionais, sociais e subjetivos na construção do conhecimento, seja ele clínico ou experimental. Em suma, do ponto de vista de uma nova forma histórica de entendimento, é necessário estabelecer relações mais nítidas e pertinentes entre o que ocorre nos contextos de pesquisa e o que povoa os contextos institucionais e sociais. 
Isso poderia, sem dúvida, implicar em grandes dificuldades, uma vez que a inclusão de processos tão subjetivos que, em uma perspectiva tradicional (Latour, 1995), deveriam ser eliminados do cenário metodológico e teórico, poderia comprometer a legitimidade dessa noção de ciência, ainda tão frágil e imprecisa na psicologia. Entretanto, essa mudança de perspectiva necessita conceber que a inclusão de noções e processos que remontam a questões de ordem política (Stengers, 2000) não consiste em intrusões indesejadas capazes de contaminar a fidedignidade dos procedimentos, mas em constituintes efetivos da construção do conhecimento psicológico. Embora o político não deva ser compreendido como a dimensão que define essencialmente os limites do que seja ou não científico, sua colocação em pauta da construção desse saber consiste em uma forma lúcida de modificar a postura ingênua com que freqüentemente os psicólogos concebem a história de sua ciência.

\section{Referências}

Bachelard, G. (1938). La formation de l'esprit scientifique. Paris: Vrin.

Bailly, J. -S. (2004a). Rapport des commissaires chargés par le roi de l'examen du magnétisme animal. In A. Bertrand (Org.), Dumagnétisme animalen France (pp.70-116). Paris: Harmattan. (Originalement publié dans1826).

Bailly, J.-S. (2004b). Rapport secret sur le mesmérisme, ou magnétisme animal. In A. Bertrand (Org.), Du magnétisme animal en France (pp.235-240). Paris: Harmattan. (Originalement publié dans1826).

Barrucand, D. (1987). Histoire de l'hypnoseen France. Paris: Puf.

Benjafield, J. G. (1996). A history of psychology. Boston: Allyn \& Bacon.

Bergé, C. (1995). L'au-delà et les lyonnais. Lyon: Ludg.

Bersot, H. (2005). Mesmer et le magnétisme animal. In S. Nicolas (Org.), Mémoire sur la découverte du magnetisme animal (pp.xxvii-cxxviii). Paris: Harmattan. (Originalement publié dans 1853).

Bertrand, A. (2004). Du magnétisme animal en France. Paris: Harmattan. (Originalement publié dans1826).

Carroy, J. (1991). Hypnose, suggestion et psychologie. L'Invention du sujet. Paris: Puf.

Carroy, J. (1993). Magnétisme, hypnose et philosophie. In I. Stengers (Org.), Importance de l'hypnose (pp.169-192). Paris: Puf.

Castoriadis, C. (2000). A instituição imaginária da sociedade. São Paulo: Paz e Terra.

Chertok, L. (1989). Hypnose et suggestion. Paris: Puf.
Chertok, L., \& Stengers, I. (1989). Le Coeuret la raison. L'hipnose en question. De Lavoisier à Lacan. Paris: Payot.

Chertok, L., \& Saussure, R. (1996). Naissance du psychanalyste. Paris: Synthélabo.

Crabtree, A. (1993). From Mesmer to Freud: magnetic sleep and the roots of psychological healing. New Haven: Yale University Press.

Darntorn, R. (1968). Mesmerism and the end of enlightenment in France. Cambridge: Harvard University Press.

Deleuze, J. P. F. (2004). Histoire critique du magnétisme animal. Paris: Harmattan. (Originalement publié dans 1813).

Demo, P. (1998). Conhecimento moderno. Petrópolis: Vozes.

Demo, P. (2000). Metodologia do conhecimento científico. São Paulo: Atlas.

Edelman, N. (1995). Voyantes, guérisseuses et visionaires en France (1785-1914). Paris: Albin Michel.

Ellenberger, H. (1970). The discovery of the unconscious. The history and evolution of dynamic psychiatry. New York: Basic Books.

Esdaile, J. (1989). Mesmerism in India. And its practical application in surgery and medicine. New Delhi: Asian Educational Services. (Original work published 1846).

Figueiredo, L. C. (1992). A Invenção do psicológico. Quatro séculos de subjetivação (1500-1900). São Paulo: Escuta.

Figueiredo, L. C. (1996). Revisitando as psicologias. Petrópolis: Vozes.

Fourez, G. (1995). A construção das ciências. São Paulo: Unesp.

Freud, S. (1996a). Análise terminável e interminável. Obras psicológicas completas de Sigmund Freud (Vol XXIII, pp.247-287). Imago: Rio de Janeiro. (Originalmente publicado em 1937).

Freud, S. (1996b). Obras psicológicas completas de Sigmund Freud. Imago: Rio de Janeiro (Originalmente publicado em 1937).

Gay, P. (2002). Freud: uma vida para nosso tempo. São Paulo: Companhia das Letras.

Gergen, K. (1996). Realidad y relaciones. Barcelona: Paidós.

Gonzalez Rey, F. (1997). Epistemología Cualitativa y Subjetividad. Havana: Pueblo y Educación.

Gonzalez Rey, F. (2005). Pesquisa qualitative e subjetividade. São Paulo: Thomson.

Hacking, I. (1999). The social construction of what? Massachusetts: Harvard University Press.

Jussieu, L. (2004). Rapport de l'un des comissaires charges par le roi de l'examen du magnétisme animal. In A. Bertrand (Org.), Du magnétisme animal en France (pp.119-150). Paris: Harmattan. (Originalement publié dans1826).

Koyré, A. (1971). Mystiques allemands du XVI siècle. Paris: Gallimard.

Latour, B. (1995). La science en action. Paris: Gallimard.

Laurence, J.-R., \& Perry, C. (1988). Hypnosis, will \& memory. A psycho-legal history. New York: Guilford Press. 
Marx, M., \& Hillix, W. (1978). Sistemas e teorias em psicologia. São Paulo: Cultrix.

Méheust, B. (1999). Somnambulisme et médiumnité. Le défi du magnétisme. Paris: Synthélabo/Seuil.

Melchior, T. (1998). Créer le reel. Hypnose et thérapie. Paris: Seuil.

Mesmer, F. A. (2005). Mémoiresurla découverte du magnétisme animal. In S. Nicolas (Org.), Mémoire sur la découverte du magnétisme animal (pp.2-85). Paris: Harmattan. (Originalement publié dans 1779).

Morel, P., Bourgeron, J. P., \& Roudinesco, E. (2000). Au-delà du conscient. Histoire illustrée de la psychiatrie et de la psychanalyse. Paris: Hazan.

Morin, E. (1991). La méthode IV. Les idées. Paris: Seuil.

Neubern, M. (2000). As emoções como caminho para uma epistemologia complexa da psicologia. Psicologia:Teoria \& Pesquisa, 16 (2), 153-164.

Neubern, M. (2003). La psychologie clinique dans la crise du paradigme dominant: du malaise aux possibilites épistémologiques. Psychothérapies, 23 (2), 81-88.

Neubern, M. (2004). Histórias que (não) curam. Sobre narrativas em hipnose clínica. Psicologia: Ciência \& Profissão, 24 (3), 58-65.

Neubern, M. (2006). Hipnose e psicologia clínica. Retomando a história não contada. Psicologia: Reflexão e Crítica, 19 (3), 346-354

Peter, J. (1999). Um somnambule désordonné. L'oeuvres du Marquis de Puységur. Paris: Synthélabo.

Popper, K. (1973). La logique de la découverte scientifique. Paris: Payot.
Puységur, A. M-J. C. (2001). Mémoires pour l'etablissement du magnétisme animal. In D. Michaux (Org.), Aux sources de l'hypnose (pp.13-131). Paris: Imago (Originalement publié dans 1784).

Roudinesco, E. (1986). La bataille de cent ans: Histoire de la psychanalyse en France. Paris: Seuil.

Santos, B. S. (1987). Um discurso sobre as ciências. Porto: Afrontamento.

Santos, B. S. (2000). A crítica da razão indolente. São Paulo: Cortez.

Schultz, D., \&Schultz, P. (1981). História da psicologia moderna. São Paulo: Pensamento.

Stengers, I. (1995). L'Invention des sciences modernes. Paris: Flammarion.

Stengers, I. (1996). La volonté de faire science. À propos de la psychanalyse. Paris: Synthélabo.

Stengers, I. (2000). As políticas da razão. Lisboa: Edições 70.

Stengers, I. (2001). Qu'est-ce que l'hypnose nous oblige à penser? Ethnopsy, 3 (13-68), 13-68.

Stengers, I. (2002). L'Hypnose: entre magie et science. Paris: Seuil.

Viney, W., \& King, B. (1998). A history of psychology. Boston: Allyn \& Bacon.

Recebido em: 27/7/2006

Versão final reapresentada em: 16/7/2007

Aprovado em: 15/8/2007 